\title{
Sería baja la tasa de transmisión de VIH entre parejas serodiscordantes con tratamiento supresivo
}

\author{
HIV transmission rate in serodiscordant couples would be low with suppressive treatment
}

\section{Objetivos}

Evaluar la tasa de transmisión de VIH intra-pareja (heterosexual y hombres que tienen sexo con hombres [HSH]) durante periodos de sexo sin preservativo/condón y cuando la pareja VIH-positivo tuviese una carga viral de ARN menor a 200 copias $/ \mathrm{mL}$.

\section{Diseño, lugar y pacientes}

El estudio observacional prospectivo PARTNER fue realizado en 75 centros en 14 países europeos entre septiembre de 2010 y mayo de 2014. Reclutó 1.166 parejas VIH sero-discordantes en las cual la pareja $\mathrm{VIH}$-positiva tomaba terapia antirretroviral (TARV) y tenía una carga viral de ARN menor a 200 copias/ $\mathrm{mL}$, y que reportaban tener sexo penetrativo sin preservativo. Cada pareja firmó un consentimiento informado donde se les informaba el riesgo de transmisión de VIH. Durante el estudio se recomendó sistemáticamente el uso de preservativo. El estudio se detenía si la pareja se disolvía pero no ante cambios en el uso de TARV.

\section{Medición de variables de exposición}

Se recolectaron datos sociodemográficos, de adherencia a la TARV, actividad sexual (frecuencia, tipo y presencia de eyaculación), enfermedades de transmisión sexual (riesgo, síntomas, presencia), uso de profilaxis pre y post exposición y también el uso de drogas inyectables. Se indagó la presencia de relaciones sexuales fuera de la pareja y el conocimiento del estatus de $\mathrm{VIH}$ de las otras parejas. Para la pareja VIH positiva se relevaron datos de carga viral y conteo de CD4.

\section{Medición de variables de resultado}

Las parejas VIH negativas se realizaron análisis periódicos de antígeno y anticuerpo cada seis y doce meses. En el caso de producirse seroconversión, se realizó análisis comparativo filogenético de las polimerasas $\mathrm{VIH}-1$ y las secuencias de la envoltura para determinar las transmisiones vinculadas filogenéticamente.
Rodger y col. JAMA. 2016;316(2):171-181.

\section{Resultados}

De las 1.166 parejas reclutadas, 888 parejas (edad media de 42 años, $61,7 \%$ parejas heterosexuales, $38,3 \%$ parejas $\mathrm{HSH}$ ) proveyeron 1.238 parejas-años de seguimiento -mediana de seguimiento 1,3 años, rango intercuartilo (IQ) de 0,8 a 2 (116 parejas no proveyeron información debido a la falta de testeo de $\mathrm{VIH}$ en la pareja seronegativa). La mediana de tiempo de sexo sin preservativo reportado fue de dos años (IQ 0,5 a 6,3). Los principales motivos para no utilizar preservativo fueron: concepción de bajo riesgo de transmisión, actividad sexual más placentera o deseo de embarazo (en mujeres). El 33\% de las parejas $\mathrm{HSH}$ y el $4 \%$ de las parejas heterosexuales refirieron tener sexo sin preservativo con otras parejas. Durante el seguimiento se reportó una mediana de 37 relaciones sexuales sin preservativo por año (IQ 15 a 71). El total en las parejas HSH fueron 22.000 actos sexuales y 36.000 en parejas heterosexuales. A pesar de que 11 parejas $\mathrm{VIH}$-negativo tuvieron seroconversión a $\mathrm{VIH}$ positivo (10 HSH, 1 heterosexual), no hubo transmisión filogenéticamente vinculada a su pareja VIH positiva durante los años de seguimiento, por lo cual la tasa de transmisión intra-pareja fue cero (IC 95\% 0 a 0,3/100 parejas-año).

\section{Conclusiones}

Entre parejas HSH y heterosexuales serodiscordantes en el que el individuo VIH positivo estaba en tratamiento antirretroviral supresivo, y durante una mediana de seguimiento de 1,3 años, no se documentaron casos de transmisión intra-pareja. Es necesario el seguimiento a largo plazo para identificar estimativos de riesgo más precisos.

Fuente de financiamiento: National Institute for Health Research (NIHR), Danish National Research Foundation. Conflictos de interés: varios de los autores reportaron haber recibido honorarios de varias compañías farmacéuticas.

\section{Comentario}

Una limitación relevante de este estudio, fue la imposibilidad que tuvieron los investigadores de recolectar información serológica de 116 parejas negativas en el seguimiento (10\% de la muestra), lo que debilita la conclusión de que el riesgo de transmisión haya sido realmente nulo. Los autores de este trabajo asumieron que este 10 $\%$ de la muestra tiene la misma probabilidad de haberse contagiado que el $90 \%$ que sí fue testeado, lo que es a primera impresión discutible. Por otro lado, vale destacar algunas consideraciones con implicancias vinculares y éticas. Por ejemplo, aún en el supuesto caso de que, tal como concluye este estudio, "...el riesgo de transmisión entre parejas serodiscordantes, cuando la persona VIH positiva posee menos de 200 copias $/ \mathrm{ml}$, sea realmente igual a cero..."; existe la posibilidad, si la persona que era VIH negativa se convierte en positiva, de que la responsabilidad recaiga sobre su pareja, por más que la persona que seroconvirtió se haya contagiado de otra personas y no de su pareja estable. Dicho de otra forma, a pesar de que las estadísticas de las investigaciones en salud brinden alta seguridad de que la probabilidad de seroconversión es extremadamente baja si la persona índice tiene carga viral baja, recordamos que en la vida real juegan un papel importante los sentimientos y las emociones, lo que podría conducir a una crisis de una relación sentimental en el caso de que el miembro de la pareja previamente negativo, seroconvirtiera.

\section{Conclusiones de los comentadores}

Consideramos que esta investigación es un gran avance en el conocimiento de los efectos positivos de la medicación antirretroviral. Sin embargo, proponemos que el equipo de salud siga recomendando el uso de métodos de barrera como protección de las relaciones sexuales en parejas serodiscordantes, dado que hoy todavía no contamos en la práctica clínica habitual la posibilidad de tipificar la cepa de VIH con la que se ha infectado una persona y poder zanjar las inquietudes/sospechas que este evento podría desencadenar respecto de cuál fue la fuente real de contagio de la persona recientemente infectada. Además, los métodos de barrera también permiten disminuir el riesgo de transmisión de otras enfermedades de transmisión sexual. Sin embargo, si luego de ser informada de estas cuestiones, la pareja serodiscordante de una persona con infección por VIH decide, aun así, no utilizar preservativo; contamos con mayor información para explicarles a ambos que la probabilidad de contagio es baja.

Mariano Massone [ Persona que vive con VIH. Periodista de Corresponsales Clave. marianomassone@gmail.com ]

Juan Victor Ariel Franco [ Servicio de Medicina Familiar y Comunitaria del Hospital Italiano del Hospital Italiano de Buenos Aires juan.franco@ hospitalitaliano.org.ar

Massone M. Franco JVA. Sería baja la tasa de transmisión de VIH entre parejas serodiscordantes con tratamiento supresivo. Evid Act Pract Ambul. 2017;20(1):13. Comentado de: Rodger AJ, y col. Sexual activity without condoms and risk of HIV transmission in serodifferentcouples when the HIV-positive partner is using suppressive antiretroviral therapy. JAMA. 2016;316(2):171-181. PMID: 27404185. 